\title{
High Quality Tissue Miniarray Technique Using a Conventional TV/Radio Telescopic Antenna
}

\author{
Mohamed A Elkablawy ${ }^{1,2 *}$, Abdulkader M Albasri²
}

\begin{abstract}
Background: The tissue microarray (TMA) is widely accepted as a fast and cost-effective research tool for in situ tissue analysis in modern pathology. However, the current automated and manual TMA techniques have some drawbacks restricting their productivity. Our study aimed to introduce an improved manual tissue miniarray (TmA) technique that is simple and readily applicable to a broad range of tissue samples. Materials and Methods: In this study, a conventional TV/radio telescopic antenna was used to punch tissue cores manually from donor parafin embedded tissue blocks which were pre-incubated at $40^{\circ} \mathrm{C}$. The cores were manually transferred, organized and attached to a standard block mould, and filled with liquid paraffin to construct $T \mathrm{~mA}$ blocks without any use of recipient paraffin blocks. Results: By using a conventional TV/radio antenna, it was possible to construct $\mathrm{TmA}$ paraffin blocks with variable formats of array size and number (2-mm x 42, 2.5-mm x 30, 3-mm x 24, 4-mm x 20 and 5-mm x 12 cores). Up to 2-mm x 84 cores could be mounted and stained on a standard microscopic slide by cutting two sections from two different blocks and mounting them beside each other. The technique was simple and caused minimal damage to the donor blocks. H\&E and immunostained slides showed well-defined tissue morphology and array configuration. Conclusions: This technique is easy to reproduce, quick, inexpensive and creates uniform blocks with abundant tissues without specialized equipment. It was found to improve the stability of the cores within the paraffin block and facilitated no losses during cutting and immunostaining.
\end{abstract}

Keywords: Manual technique - tissue microarray - antenna sampling - immunostaining

Asian Pac J Cancer Prev, 16 (3), 1129-1133

\section{Introduction}

The invention of tissue microarrays TMAs and commercialization of this technique is a boon for scientists and pathologists who, without this technique, would spend too much time studying numerous tests done by conventional methods (Singh and Sau, 2010). Nevertheless, the major focus of TMAs at the present time is in the fields of cancer and non-cancer research; and quality control in modern pathology (Avninder et al., 2008; Jawhar, 2009). It has greatly facilitated the in situ analysis of molecular targets at the DNA, mRNA, and protein levels under standardized conditions in a large number of archived pathology specimens (Fowler et al., 2011).

Advances of the technique enables pathologists to perform large-scale analyses using immunohistochemistry, fluorescence in situ hybridization (FISH), or RNA in situ hybridization (ISH) at substantially faster and markedly lower costs compared with conventional approaches (Brown and Huntsman, 2007; Faratian et al., 2009; Veek and Dahl, 2010). Microarrays of different tissues were widely used for detection of different immunostaining markers such as p53, bcl2, HER2, E-cadherin, ER, PR, Ki67 and others (Cass et al., 2012; Laurinavicius et al.,
2012; Syed et al., 2013; Azlin et al., 2014; Rakhshani et al., 2014). Several efforts have been made by many researchers in the last 15 years, to develop and improve the output of the TMA technique. The specialized commercial automated and semi- automated equipments as well as the inexpensive simple manual tissue array methods have been used to construct the TMA blocks (Faratian et al., 2009; Veek and Dahl, 2010; Fowler et al., 2011; Foda, 2013). However, up till now, the productivity of TMA has been restricted in developing countries allover the world due to the costs of available arrayers and technical difficulties of routine array construction (Shebl et al., 2011; Choi et al., 2012).

The small size of TMA cores may not be representative of the whole heterogeneous cancers and may not provide enough data about the entire tissue profile (Eckel-Passow et al., 2010; Kim et al., 2013). Also, sectioning difficulties, irregular cutting plane due to variable thickness of donor paraffin blocks, core losses and instability of the TMA blocks are commonly reported problems in routine TMA (Foda, 2013). So, this study was carried out in order to overcome these drawbacks and develop an easy economical method for construction of self-made manual TmAs with variable tissue formats. These arrays

${ }^{1}$ Pathology Department, Faculty of Medicine, Menoufyia University, Shibeen Elkom, Egypt, ${ }^{2}$ Pathology Department, Faculty of Medicine, Taibah University, Almadinah Al-Munawarrah, Saudi Arabia*For correspondence: elkablawy@hotmail.com 
can be constructed using materials available in every lab in developing countries and do not require specialized equipments.

\section{Materials and Methods}

\section{Self-made manual TmAs kits using the TV/Radio telescopic antenna}

Six pieces TV/Radio telescopic antenna (Figure 1) was purchased from domestic electronic shop in Almadinah AlMunawarrah, Saudi Arabia for 5 SR =1.3\$. The telescopic pieces of the antenna were separated from each other and each 2 consecutive pieces were used as a manual TmA kit for punching out and extracting tissue cores from prewarmed donor paraffin blocks. The antennal pieces can be used for extraction of tissue cores with different diameters ( $2 \mathrm{~mm}, 2.5 \mathrm{~mm}, 3 \mathrm{~mm}, 4 \mathrm{~mm}$ and $5 \mathrm{~mm}$ ) respectively.

\section{Preparation of tissue cores}

Familiar domestic TV/Radio telescopic antenna having six telescopic segments with different sizes was used to punch paraffin tissue cores (cylindrical rods) from paraffin donor blocks (Figure 2). The blocks were pre-incubated for 5 minutes at $40-42^{\circ} \mathrm{C}$ to warm and soften the paraffin and facilitate puncture of the cores with minimal damage to the block. Perfect wax cylindrical cores were manually punched out by inserting the segment of the antenna in the donor paraffin blocks with a perpendicular angle. The cores were extracted from marked regions selected on correspondent H\&E slides overlaid. Each core was gently pressed out from the antennal segment with the following telescopic segment. Then, the core was transferred with a forceps with its surface facing down and attached to a grid pre-mapped in stainless steel standard mould.

\section{Preparation of TmA blocks}

Tissue blocks derived from breast cancer and colorectal cancer were used for array construction. The blocks were obtained from the histopathological archive of the pathology department, King Fahd hospital, Almadinah Al-Munawarrah, KSA. One core of morphologically representative tumor area was punched out manually from each paraffin block and transferred as described above to a specific site in the pre-mapped grid in stainless steel standard mould. Each cylindrical core was transferred to the mould in an orderly vertical fashion, and firmly attached to the mould using thin film of Kablawy white glue (55\% Vinyl acetate and $45 \%$ water, S-Elkablawy, El-Mahalla El-Kobra, Egypt). Normal tissue, different sized cores or position-specific blank cores can be used for orientation during microscopy. The design of each mould was detailed in a TmA map, indicating the position and identification of each core. Finally, melted paraffin wax was gently poured into the mould with all the rods attached in a perfectly vertical fashion. The formed TmA block was handled according to routine histopathological procedures.

\section{Cutting and staining}

After trimming, $4 \mu \mathrm{m}$ thick sections were obtained from the TmA blocks with the aid of ordinary microtome and ordinary warm water bath. The sections were then mounted on to appropriately electrostatically coated microscopic slides, supporting the cohesion of the array elements on the glass, incubated overnight at $40^{\circ} \mathrm{C}$ and stained with routine $H \& E$.

\section{Immunohistochemistry (IHC)}

Immunohistochemical analysis was performed at room temperature and washes were performed with TBS. $4 \mu \mathrm{m}$ tissue sections were dewaxed and rehydrated. Antigen retrieval was done using EDTA retrieval solution PH 9 in a standard microwave oven for 10 minutes. Endogenous peroxidase activity was blocked with $3 \%$ hydrogen peroxide (S2023, DAKO). Sections were then incubated with antibodies against p53 MoAb DO7 (5 $\mu \mathrm{g} / \mathrm{ml}$, Dako), Bcl-2 MoAb 124 (1,5 $\mu \mathrm{g} / \mathrm{ml}$; Dako), HER2 (DAKO, Carpinteria, USA), E-cadherin Ab-3 (Clone 36B5, Thermo Fisher Scientific, Lab Vision Corporation, Fremont, CA, USA) and rabbit monoclonal anti-human Ki-67 (Clone SP6, RM-9106-R7, ready to use, Neomarkers, Fremont, CA, USA), according to the manufacturer's instructions and the signals were visualized with diaminobenzidine (K3468, DAKO) for $10 \mathrm{~min}$.

\section{Silver-enhanced in situ hybridization}

HER2 SISH was performed on an automated instrument, a Ventana Benchmark (Ventana Medical Systems), according to the manufacturer's protocols for INFORM HER2 DNA and chromosome 17 probes. Testing for the HER2 gene and chromosome 17 was performed on sequential sections. Two sections were baked at $60^{\circ} \mathrm{C}$ for 20 minutes. The HER2 DNA probe was denatured at $95^{\circ} \mathrm{C}$ for 12 minutes and hybridization was performed at $52^{\circ} \mathrm{C}$ for 2 hours. The chromosome 17 probe was denatured at $95^{\circ} \mathrm{C}$ for 12 minutes and hybridization was performed at $44^{\circ} \mathrm{C}$ for 2 hours. After hybridization, appropriate stringency washes were performed three times at $72^{\circ} \mathrm{C}$ for the HER2 probe and three times at $59^{\circ} \mathrm{C}$ for the chromosome 17 probe. Both DNP-labeled probes were visualized using a rabbit anti-DNP primary antibody and the ultra-view SISH detection Kit (Ventana). The slides were counterstained with hematoxylin for examination by light microscopy. Evaluation of HER2 gene amplification status was performed in a blind manner using the ASCO/ CAP guidelines (Wolff et al., 2007; Wolff et al., 2013).

\section{Results}

By using the conventional TV/radio antenna, it was possible to construct manual TmAs with abundant tissues including tissue cylinders of 2-mmX42, 2.5-mmX30, 3-mmX24, 4-mmX20 and 5-mmX12 (Figure 3). H\&E showed well defined tissue morphology and array configuration without any tissue loss (Figure 4). These tissue cylinders of $\geq 2 \mathrm{~mm}$ arrayed tissues offered more tissue surface to evaluate immunostaining both in tumor cells and stroma. We successfully performed p53, bcl2, HER2, E-cadherin and Ki67 immunodetection without substantial tissue cylinder loss during antigen retrieval or washes (Figure 5a). HER2 amplification measured by silver-enhanced in situ hybridization was successfully 


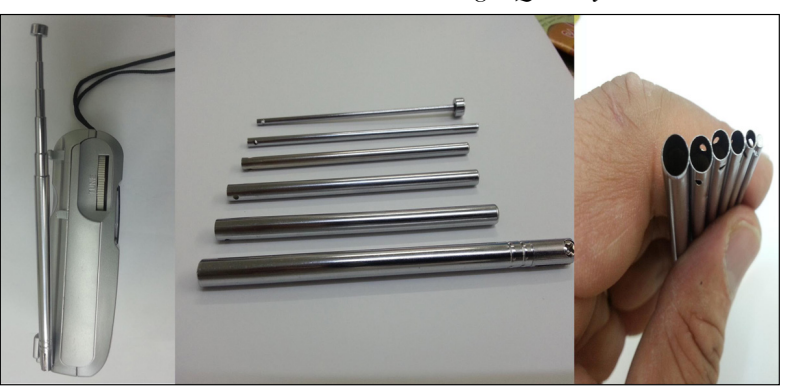

Figure 1. Six pieces Radio Antenna was Purchased from Domestic Electronic shop in Almadinah AlMunawarrah, KSA

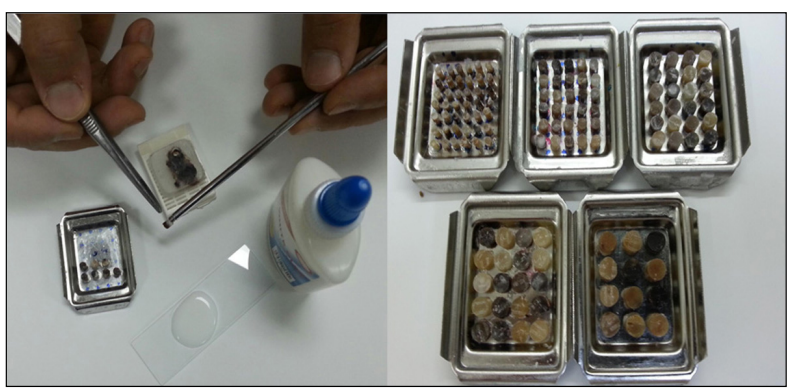

Figure 2. Each two Consecutive Antennal Segments were Used to Punch out Different Sizes Cylindrical Tissue rods (2, 2.5,3,4 and $5 \mathrm{~mm})$ from Paraffin Donor Blocks. The rods were transferred and attached with thin film of white glue to the moulds

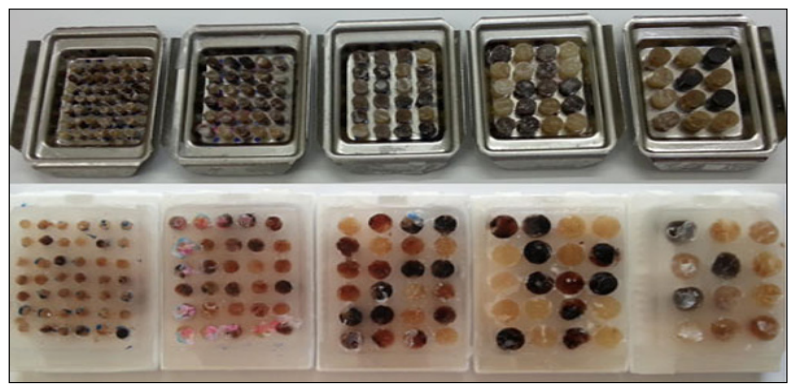

Figure 3. Macroscopic Picture of TmA Blocks and their Corresponding Moulds with Abundant Tissues Including Tissue Cylinders of 2-mmX42, 2.5-mmX30, 3-mmX24, 4-mmX20 and 5-mmX12

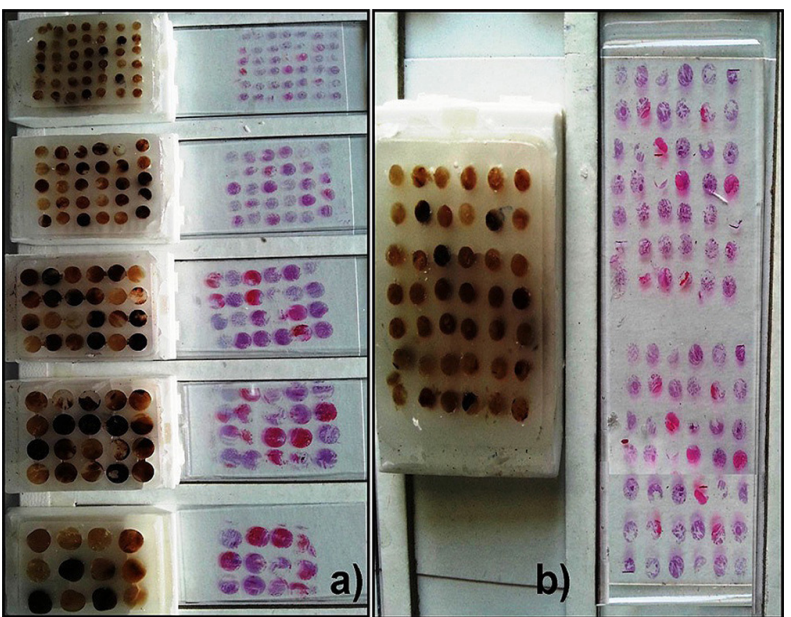

Figure 4. a) TMA Blocks and the Corresponding H\&E

Stained Slides of five Tissue Microarrays. b) Up to 84 cores on one microscopic slide [2 H\&E stained sections of ( $2 \mathrm{~mm} \mathrm{X42} \mathrm{cores)]}$

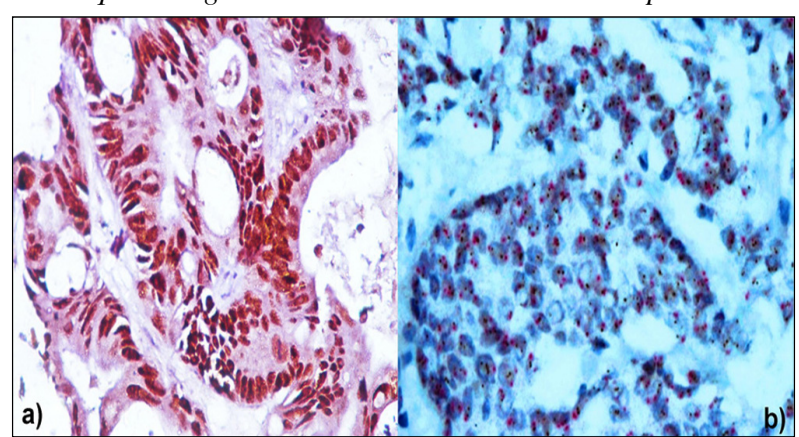

Figure 5. (A) Nuclear staining of p53 of one core of Multiple tumor Arrays of Breast Cancer (DAB, $\times$ 400). (B) HER2 amplification measured by silver-enhanced in situ hybridization in breast cancer

observed in the studied breast cancers (Figure 5b).

\section{Discussion}

The era of tissue microarrays has just begun. It will only be a question of time before TMAs find their role as an integral part of daily practice in routine clinical laboratories. However, the expensive array construction and high cost of commercial array equipments, have been restricted the global use of this technique worldwide. Many researchers in developing countries made efforts to overcome the high cost, through in-house manual construction of high-density TMAs (Shebl et al., 2011; Choi et al., 2012; Foda, 2013; Kim et al., 2013). However, minor drawbacks including, variable degrees of section distortion, small tissue core size, irregular cutting plane and loss of the tissue cores can occur during cutting of the TMAs, posing technical problems for in-house manual construction of TMAs (Eckel-Passow et al., 2010; Foda, 2013).

Our TV/Radio antenna technique aimed to update the manual TMA construction, overcome the reported drawbacks and improve the quality of TMAs. The cost of our simple method is very cheap $<1$ \$ USD for 2-mm X 42 core paraffin tissue arrays, which we recommend as an ideal number per TmA block in our method. These relatively large core sizes have the advantages of being more tissue robust and less likely to damage during handling. We could overcome the problems of irregular cutting planes and section distortion as the cores were glued to the mould at the same plane. We could also overcome the difficulty of large core extraction and the chance of blocks being broken or cracked during TmA construction by pre-warming the blocks up to $42{ }^{\circ} \mathrm{C}$ in oven or water bath. By comparing our technique with other tissue microarrays, this technique is a simple, fast and inexpensive alternative to construct small format TmAs for use in research in developing countries. Regarding the size and number of the tissue cores per block, our 2-mm x 42 cores TmA block could be enough to represent 42 cases (one core per case) with abundant tissue cells and stroma. While these 42 cases in other techniques would be represented by TMA block containing 0.6-mm x 126 small tissue cores (three cores per case) with the disadvantage of inadequate stroma and core loss. Many researchers reported up to $20 \%$ core loss during sectioning and 
staining in TMA techniques with large number of small cores (Foda, 2013; Kim et al., 2013). It was also difficult to study facet of tumor biology such as interactions between the tumor and its stroma as these stromal components may not be adequately represented in small cores (Singh and Sau, 2010; Foda, 2013). Our technique could overcome this problem and there was no loss of any tissue cores during cutting or staining processes as the cores were large and incorporated very well in the TmA blocks. Also, the use of large cores ( $2 \mathrm{~mm}$ ) maintained robust tissues for studying many histological features and offered more tissue surface area to evaluate immunostaining both in cells and stroma.

It may be argued that small format TMAs might not be ideal for high-throughput analysis of biomarker expression in which a very large number of tissue cores have to be analyzed at the same time to minimize run-to-run variability. We could overcome this problem by mounting two sections of $2-\mathrm{mm} \times 42$ cores beside each other to produce $2-\mathrm{mm} \times 84$ cores on one standard microscopic slide. In other TMA methods, this will be represented by $0.6-\mathrm{mm} \times 252$ cores. Even though we recommend the 2-mm x 42 core TmA, It is easy to modify the diameter and the number of cores in the array according to individual lab requirements. One size does not fit all (Eckel-Passow et al., 2010).

The immunostaining detection and the staining patterns of p53, bcl2, HER2, E-cadherin and Ki67 in our breast cancer TmA were studied in cancer cells and stroma as well as in cytoplasm and nuclei; and semi-quantitatively represented as previously reported (Elkablawy et al., 2001; Wolff et al., 2007; Rakhshani et al., 2014). The results were in concordance with previously published data regarding immunostaining expression of $\mathrm{p} 53, \mathrm{bcl} 2$, HER2, E-cadherin and Ki67 in tissue microarrays (Cass et al., 2012; Laurinavicius et al., 2012; Syed et al., 2013; Azlin et al., 2014). Also, the results obtained with SISH for measuring HER2 amplification in the current study were consistent with those of other studies using SISH for HER2 assay (Papouchado et al., 2010; Wolff et al., 2013).

In conclusion, we introduced an improved new manual tissue miniarray (TmA) technique that is simple, easy to reproduce and created uniform blocks with abundant tissues without specialized equipment and without any use of premade recipient paraffin blocks. We think that this technique would be of interest and great help to thousands of pathologists with poor research fund in developing countries. It can be performed by any anatomic pathology laboratory, at low cost and requiring minimum skill and time. It will encourage young researchers in developing countries to perform TMA with fewer expenses.

\section{Acknowledgements}

The authors thank the Deanship of Scientific research of Taibah University, Almadinah Al-Munawarrah, Saudi Arabia, for their encouragement and support. The authors thank Sarah Elkablawy (Second year student in Faculty of Pharmacy, Tanta University, Egypt) for gum preparation and dedication; Dr. Nashaat Zaki and Dr. Akbar Haussainy for reviewing the grammer of manuscript. Also, authors thank Mr. Mohamed Abdelsammad (Microbiology Lab., Taibah University, KSA), Mr. Mohammed Farouq and Mr. Bahgat Ali (Pathology Lab., Gynecology \& Obstetric Hospital, Almadinah Al-Munawarrah, KSA) for technical advice.

\section{References}

Avninder S, Ylaya K, Hewitt SM (2008). Tissue microarray: a simple technology that has revolutionized research in pathology. J Postgrad Med, 54, 158-62.

Azlin AH, Looi LM, Chea PL (2014). Tissue microarray immunohistochemical profiles of p53 and pRB in hepatocellular carcinoma and hepatoblastoma. Asian Pac $J$ Cancer Prev, 15, 3959-63.

Brown LB, Huntsman D (2007). Fluorescent in situ hybridization on tissue microarrays: challenges and solutions. J Mol Hist, 38, 151-7.

Cass JD, Varma S, Day AG, et al (2012). Automated quantitative analysis of p53, Cyclin D1, Ki67 and perk expression in breast carcinoma does not differ from expert pathologist scoring and correlates with clinico-pathological characteristics. Cancer, 18, 725-42.

Choi CH, Kim KH, Song JY, et al (2012). Construction of highdensity tissue microarrays at low cost by using self-made manual microarray kits and recipient paraffin blocks. Korean J Pathol, 46, 562-8.

Eckel-Passow JE, Lohse CM, Sheinin Y, et al (2010). Tissue microarrays: one size does not fit all. Diagn Pathol, 5, 48-58.

Elkablawy MA, Maxwell P, Williamson K, Anderson N, Hamilton PW (2001). Apoptosis and cell-cycle regulatory proteins in colorectal carcinoma: relationship to tumour stage and patient survival. J Pathol, 194, 436-43.

Faratian D, Graham A, Rae F, Thomas J (2009). Rapid screening of tissue microarrays for HER-2 fluorescence in situ hybridization testing is an accurate, efficient and economic method of providing an entirely in situ hybridization-based HER-2 testing service. Histopath, 54, 428-32.

Foda A M (2013). No-cost manual method for preparation of tissue microarrays having high quality comparable to semiautomated methods. Appl Immunohistochem Mol Morphol, 21, 271-4.

Fowler CB, Man YG, Zhang S, et al (2011). Tissue microarrays: construction and uses. Methods Mol Biol, 724, 23-35.

Jawhar NM (2009). Tissue microarray: a rapidly evolving diagnostic and research tool. Ann Saudi Med, 29, 123-7.

Kim KH, Choi SJ, Choi YI, et al (2013). In-house manual construction of high-density and high-quality tissue microarrays by using homemade recipient agarose-paraffin blocks. Korean J Pathol, 47, 238-44.

Laurinavicius A, Laurinaviciene A, Ostapenko V, et al (2012). Immunohistochemistry profiles of breast ductal carcinoma: factor analysis of digital image analysis data. Diagn Pathol, 7, 27-42.

Papouchado BG, Myles J, Lloyd RV, et al (2010). Silver in situ hybridization (SISH) for determination of HER2 gene status in breast carcinoma: comparison with FISH and assessment of interobserver reproducibility. Am J Surg Pathol, 34, 767-76.

Rakhshani N, Kalantari E, Bakhti H, Sohrabi MR, Mehrazma M (2014). Evaluation of HER-2/neu overexpression in gastric carcinoma using a tissue microarray. Asian Pac J Cancer Prev, 15, 7597-602.

Shebl AM, Zalata KR, Amin MM, El-Hawary AK (2011). An inexpensive method of small paraffin tissue microarrays using mechanical pencil tips. Diagn Pathol, 6, 117-21. 
Singh A, Sau AK (2010). Tissue microarray: a powerful and rapidly evolv $\neg$ ing tool for high-throughput analysis of clinical specimens. Int $J$ Case Rep Images, 1, 1-6.

Syed BM, Green AR, Paish EC, et al (2013). Biology of primary breast cancer in older women treated by surgery: with correlation with long-term clinical outcome and comparison with their younger counterparts. Br J Cancer, 108, 1042-51.

Veeck J, Dahl E (2010). RNA expression analysis on formalinfixed paraffin embedded tissues in TMA format by RNA in situ hybridization. Methods Mol Biol, 664, 135-50.

Wolff AC, Hammond ME, Schwartz JN, et al (2007). American Society of Clinical Oncology/College of American Pathologists guideline recommendations for human epidermal growth factor receptor 2 testing in breast cancer. J Clin Oncol, 25, 118-45.

Wolff AC, Hammond ME, Hicks DG, et al (2013). Recommendations for human epidermal growth factor receptor 2 testing in breast cancer: American Society of Clinical Oncology/College of American Pathologists clinical practice guideline update. J Clin Oncol, 31, 3997-4013. 